\title{
STRATEGI PENINGKATAN BRAND AWARENESS YANG DILAKUKAN OLEH LE MINERALE SELAMA MASA PANDEMI COVID-19
}

\author{
Hasto Bimo Aji ${ }^{1}$, Witrie Nuringtyas Gita $\mathbf{A}^{\mathbf{2}}$ \\ London School of Public Relations Communication \& Business Institute \\ Email: hastobimo10@gmail.com
}

\begin{abstract}
ABSTRAK
Perkembangan teknologi pada zaman ini memunculkan sederetan fenomena kehidupan terkini dan terbaru yang serba digital di sejumlah bidang. Penggunaan media sosial untuk meningkatkan brand awareness dan penjualan online sudah tidak bisa dipungkiri. Sebab, mayoritas penduduk di Indonesia, terutama generasi milennial, saat ini adalah pengguna aktif media sosial. Melihat fenomena sosial media dan menanggapi pandemic Covid-19 yang mengharuskan masyarakat untuk tetap dirumah membuka kesempatan untuk sebuah brand memenuhi kebutuhan beriklannya melakukan product placement sebagai cara untuk meningkatkan brand awareness seperti yang telah dilakukan oleh Le Minerale. Adapun tujuan dari penelitian ini adalah untuk mengetahui strategi product placement yang digunakan le minerale agar menjadi top of mind. Penelitian ini menggunakan metodologi kualitatif deskriptif. Hasil dari penelitian ini adalah dengan adanya pandemic Covid-19 ini, product placement yang digunakan oleh Le Minerale dapat meningkatkan brand awareness dimana orang banyak menghabiskan waktu dirumah dan lebih banyak menggunakan internet untuk menonton YouTube atau program televisi sehingga kedepannya cara yang dilakukan oleh Le Minerale dalam penempatan produknya dapat digunakan oleh brand lain untuk mempromosikan produk nya melalui social media atau media lainnya.
\end{abstract}

Kata Kunci: Brand Awareness, Product Placement, Le Minerale, Covid-19, Strategi

\section{THE BRAND AWARENES STRATEGY LAUNCHED BY LE MINERAL DURING THE COVID PANDEMIC}

\begin{abstract}
The development of technology in this era gave rise to a series of the latest and most recent digital life phenomena in a number of fields. The use of social media to increase brand awareness and online sales is inevitable. Because, the majority of the population in Indonesia, especially the millennial generation, is currently an active user of social media. Seeing the social media phenomenon and responding to the co-19 pandemic that requires people to stay at home opens the opportunity for a brand to fulfill its advertising needs to do product placement as a way to increase brand awareness as Le Minerale has done. The purpose of this study is to determine the product placement strategy used by Le Minerale to be the top of mind. This research uses descriptive qualitative methodology. The results of this study are the existence of the Covid-19 pandemic, product placement used by Le Minerale can increase brand awareness where people spend more time at home and use the internet more to watch YouTube or television programs so that in the future Le Minerale's method in its product placement can be used by other brands to promote its products through social media or other media.
\end{abstract}

Keywords: Brand Awareness, Product Placement, Le Minerale, Covid-19, Strategy 
Korespondensi: Witrie Nuringtyas Gita A. The London School of Public Relations Jakarta. Sudirman Park Campus Jl. K.H. Mas Mansyur Kav.35 Jakarta Pusat 10220, Indonesia. No. HP : 087878778989, Email : hastobimo10@gmail.com

\section{PENDAHULUAN}

Perkembangan teknologi pada zaman ini memunculkan sederetan fenomena kehidupan terkini dan terbaru yang serba digital di sejumlah bidang. Adapun pemanfaatan internet di era global sebagai wujud kemajuan teknologi digital terhadap visi modernisasi informasi kian merebak drastis terutama dalam hal pemenuhan kebutuhan masyarakat informasi di bidang sosial ekonomi, politik, budaya, dan lainnya. Ditinjau dari sisi bisnis, pemanfaatan media online yang lazimnya disebut social media atau media sosial yang sangat berarti bagi para pelaku pasar, investor, ataupun pelaku industri (Tasruddin, 2017)

Penggunaan media sosial untuk meningkatkan branding dan penjualan online sudah tidak bisa dipungkiri. Sebab, mayoritas penduduk di Indonesia, terutama generasi milenial, saat ini adalah pengguna aktif media sosial. Alasan lain adalah efektifitas pemasaran. Berbagai platform di media sosial saat ini sudah menyediakan fitur ads atau beriklan dengan sasaran dan target yang sangat spesifik. Dengan fitur ini perusahaan atau penjual online bisa melakukan promosi secara efektif (Arif, 2020, 20 April). Product placement yang biasanya dilakukan ditelevisi maupun film sekarang membuka kemungkinan untuk melakukannya didalam media sosial, yakni youtube.

Product placement memiliki defiisi sebagai suatu praktek penempatan produk bermerek, kemasan atau barang merek dagang lain-nya pada sebuah film, program televisi, atau media digital lainnya yang bertujuan untuk meningkatkan ingatan akan merek dan secara singkat dapat mempermudah dalam pengenalan suatu produk di suatu lokasi pembelian. Berdasarkan pengertian tersebut, dapat diinterpretasikan bahwa product placement me-rupakan perkembangan strategi marketing yang tidak lagi menggunakan iklan konvensional, namun mengikuti perkembangan media komunikasi masa yang adalah media yang bergerak atau bersuara seperti radio, televisi, internet, dan media digital lainnya (Panda, 2004). Adapun product placement yang sebelumnya telah dilakukan oleh brand Le Minerale yakni seperti pada acara televise ILC (Indonesia Lawyers Club), serta melakukan product placement melalui kafe atau restaurant, sekarang le minerale melakukan product placement pada channel-channel youtube.

Youtube adalah sebuah media sosial yang kontennya adalah video, memberikan perangkat atau fasilitas pembuatan kanal atau channel. Kanal ini dimiliki oleh khalayak yang telah memiliki akun. Di kanal ini pengguna bisa mengunggah video berdasarkan kategori maupun jenis yang diinginkan. Ibarat sebuah kanal stasiun televisi di perangkat TV, kanal yang dibentuk oleh pengguna ini merupakan gambaran atau sebagai modal produksi dari TV secara mikro di media sosial. YouTube ialah ruang virtual menjadi lokasi di mana interaksi sosial berjalan dan virtual society itu ada (Nasrullah, MEDIA SOSIAL (Perspektif Komunikasi, budaya, dan sosioteknologi), 2017). 


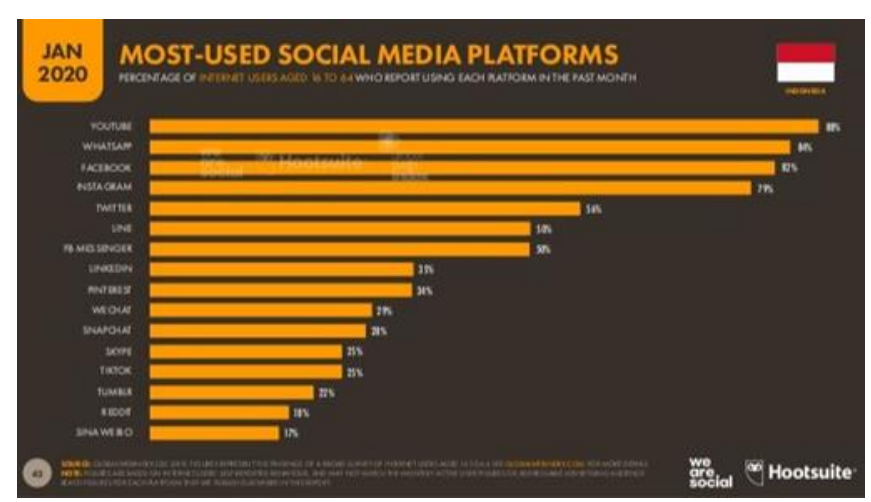

Gambar 1: Data Sosial Media Platform Yang Sering Digunakan (Sumber: Hootsite: Indonesian Digital Report 2020)

Berdasarkan data diatas, youtube menduduki peringkat pertama artinya youtube merupakan platform sosial media yang paling aktif dan paling banyak digunakan oleh masyarakat Indonesia.

Melalui informasi dari laman Social Blade, terdapat daftar peringkat 100 YouTubers di Indonesia, yang diurut berdasarkan jumlah subscriber-nya (pelanggan tontonan suatu saluran di YouTube). Sedikit catatan: akun YouTube resmi saluran televisi, program televisi, dan label rekaman musik dikecualikan dari daftar tersebut. Berdasarkan pengolahan data tersebut, sebanyak 7 dari 10 YouTubers yang populer di Indonesia muncul dengan konten bergenre video blogging atau "vlog," yakni bentuk blog yang menggunakan medium video. Akun "Rans Entertainment" merupakan akun youtubel yang memiliki lebih dari 14 juta subscriber, saluran milik pasangan selebriti Nagita Slavina dan Raffi Ahmad, juga masuk dalam kategori YouTubers yang populer dengan konten vlog (kurniawan, 2019, 3 Juli).

Ditengah pandemi Wabah Covid-19 dan juga kebijakan seperti penerapan pembatasan sosial berskala besar (PSBB) yang dilakukan oleh pemerintah yang terjadi di sejumlah wilayah di Indonesia membuat masyarakat tak bisa leluasa keluar rumah. Anjuran untuk dirumahaja, yang diiringi kebijakan work from home (WFH) dan school from home, membuat masyakarat lebih banyak menghabiskan waktu mereka di rumah. Hal ini membuat aktivitas masyarakat di media sosial terus meningkat dan ini juga merupakan kesempatan bagi para pengusaha baik skala besar maupun skala usaha kecil dan menengah (UKM) tetap bertahan dengan meningkatkan penjualan online melalui media sosial (Arif, 2020, 20 April).

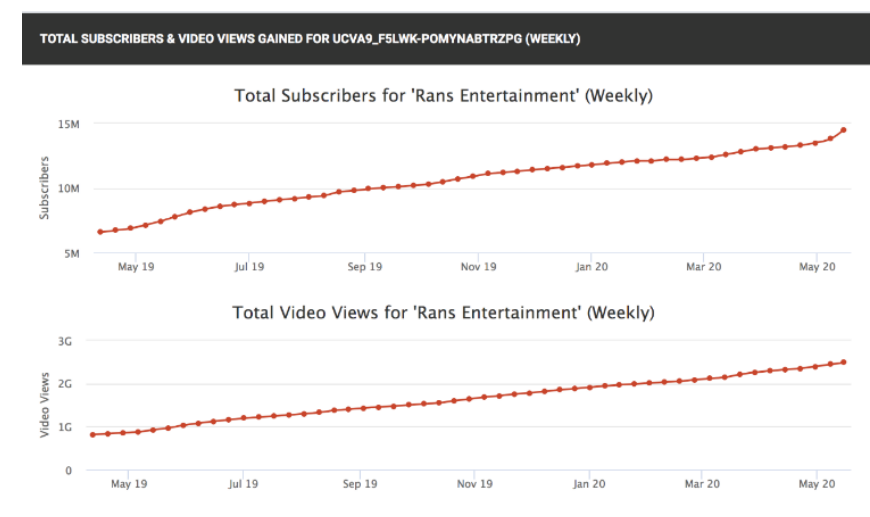

Gambar 2: YouTube Analytical History For Rans Entertainment (Sumber: SocialBlade: Youtube User Analytics 2020)

Melihat statistik penonton dan pertambahan jumlah subscriber pada youtube rans yang semakin hari semakin bertambah, maka membuka peluang yang sangat besar bagi sebuah brand atau product untuk meningkatkan brand awarenessnya salah satunya dalam hal ini adalah dengan menggunakan cara product placement (Socialblade, 2020).

\section{Brand Awereness}

Kesadaran merek (brand awareness) artinya kesanggupan seorang calon pembeli untuk mengenali atau mengingat kembali bahwa suatu merek merupakan bagian dari kategori produk tertentu (Aaker, 2010, p. 90). Brand awareness adalah sebuah aset yang sangat tahan lama dan berkelanjutan. Suatu produk yang telah dipilihkonsumen sehingga konsumen tersebut 
memilki kesadaran dominan akan produk tersebut sangatlah sulit untuk tergantikan dengan produk lainnya (Aaker, 2010, p. 177).

Menurut Aaker (2013: 205), kesadaran merek (brand awareness) adalah sebuah aset yang dapat bertahan dalam waktu yang sangat lama. Kesadaran merek (brand awareness) merupakan aset yang tidak berwujud (intangible asset), yang mencakup merek, persepsi kualitas, nama atau citra, simbol, dan slogan suatu merek yang merupakan sumber utama keunggulan bersaing di masa depan. Menurut Malik et al. (2013), kesadaran merek (brand awareness) merupakan sebuah modal yang penting, karena merupakan salah satu faktor yang mempengaruhi keputusan pembelian.

Menyadari akan pentingnya kesadaran merek (brand awareness) dalam mempengaruhi niat beli dan keputusan pembelian konsumen menyebabkan banyak perusahaan yang berlomba-lomba untuk meraih top of mind di benak konsumen, sehingga setiap harinya konsumen disesaki oleh pesan pemasaran di berbagai media yang tujuannya adalah untuk membangun sebuah kesadaran merek (brand awareness). Niat beli (purchase intention) adalah perilaku konsumen yang muncul sebagai respon terhadap objek yang menunjukkan keinginan pelanggan untuk melakukan pembelian (Kotlet dan Keller, 2012: 137). Niat beli menurut Shah et al. (2012) adalah jenis keputusan yang mempelajari secara khusus mengapa konsumen membeli sebuah merek. Niat beli adalah tahapan konsumen dalam membentuk pilihan mereka diantara beberapa merek yang tergabung dalam perangkat pilihan, kemudian pada akhirnya melakukan suatu pembelian alternatif yang paling disukainya atau proses yang dilalui konsumen untuk membeli suatu barang atau jasa yang didasari oleh bermacam pertimbangan (Annafik, 2012). Niat beli adalah evaluasi dan sikap konsumen terhadap produk dengan melihat factor eksternal sehingga berdampak pada kesediaan konsumen untuk membeli produk (Wen et al., 2013).

\section{Tingkatan Brand Awareness}

Brand awareness memiliki beberapa tingkatan dari tingkatan yang paling rendah (tidak menyadari brand) sampai tingkatan yang paling tinggi yaitu Top of Mind, yang bisa digambarkan dalam sebuah piramida. Piramida brand awareness dari rendah sampai tingkat tertinggi adalah sebagai berikut:

Gambar 3: Piramida Brand Awareness (Sumber: Durianto et al. (2004: p.55)

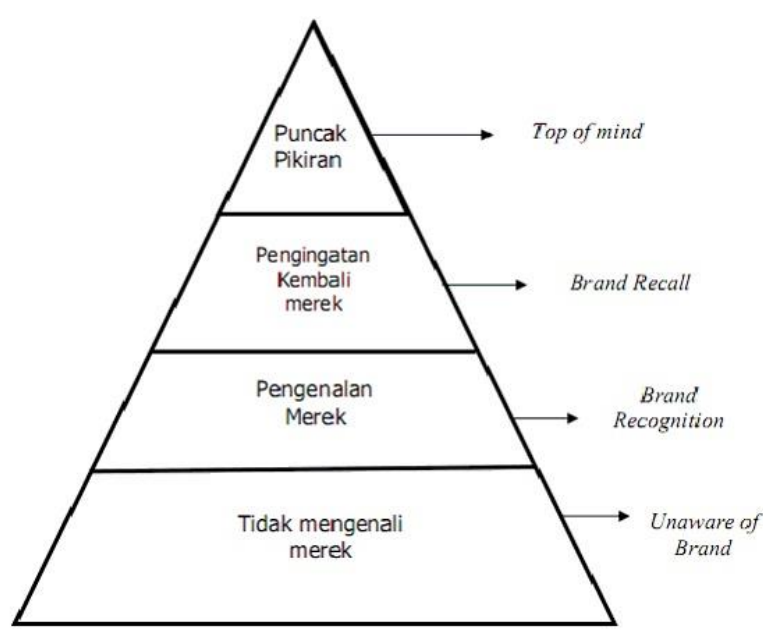

- Unware of Brand (tidak menyadari brand) adalah tingkat paling rendah dalam piramida brand awareness di mana konsumen tidak menyadari adanya suatu brand.

- Brand Recognition (pengenalan brand) adalah tingkat minimal brand awareness, di mana pengenalan suatu brand muncul lagi setelah dilakukan pengingatan kembali lewat bantuan (aided recall). 
- Brand Recall (pengingatan kembali brand) adalah pengingatan kembali brand tanpa bantuan (unaided recall).

- Top of Mind (puncak pikiran) adalah brand yang disebutkan pertama kali oleh konsumen atau yang pertama kali muncul dalam benak konsumen, atau brand tersebut merupakan brand utama dari berbagai brand yang ada dalam benak konsumen.

\section{METODE PENELITIAN}

Pada penelitian ini, jenis kualitatif yang digunakan ialah kualitatif deskriptif. Menurut Whitney yang dikutip dalam buku Metode Penelitian karangan Moh. Nazir ialah penelitian yang mencoba memahami masalah -masalah sosial yang berada pada masyarakat, baik tentang peraturan sosial yang berlaku untuk lingkungan masyarakat tersebut serta kondisi dan situasi di dalam masyarakat tersebut. Metode deskriptif ini juga menjelaskan bahwa peneliti mampu melakukan pembandingan dari sebuah fenomena fenomena yang terjadi, sehingga hal tersebut termasuk dalam studi komparatif (Nazir, 2009, p. $55)$.

Menurut Travers dalam Umar (2009) metode deskriptif adalah metode yang bertujuan untuk menggambarkan sifat sesuatu yang tengah berlangsung pada saat riset dilakukan dan memeriksa sebab-sebab dari gejala tertentu. Sedangkan menurut Gay dalam Umar (2009), metode deskriptif adalah metode yang bertujuan untuk menjawab pertanyaan yang menyangkut sesuatu pada waktu sedang berlangsungnya proses riset.

Fokus penelitian memiliki manfaat sebagai pembatas peneliti dalam meneliti sebuah objek yang diteliti sehingga data dan informasi yang masuk kepada peneliti merupakan data yang relevan dan dapat mendukung pada penelitian tersebut. Dalam penelitian kualitatif penentuan fokus lebih ditentukan dari tingkat kebaruan informasi yang akan diperoleh dari situasi sosial (lapangan). Dalam hal ini penelitian difokuskan pada strategi product placement yang dilakukan oleh le minerale untuk menaikkan Brand Awareness.

Pada penelitian ini peneliti menggunakan triangulasi metode sebagai teknik pemgumpulan data yang digunakan. Trianulasi sendiri merupakan sebuah metode untuk mengumpulkan data. Triangulasi pada hakikatnya merupakan pendekatan multimetode yang dilakukan peneliti pada saat mengumpulkan dan menganalisis data. Ide dasarnya adalah bahwa fenomena yang diteliti dapat dipahami dengan baik sehingga diperoleh kebenaran tingkat tinggi jika didekati dari berbagai sudut pandang.

Memotret fenomena tunggal dari sudut pandang yang berbeda-beda akan memungkinkan diperoleh tingkat kebenaran yang handal. Karena itu, triangulasi ialah usaha mengecek kebenaran data atau informasi yang diperoleh peneliti dari berbagai sudut pandang yang berbeda dengan cara mengurangi sebanyak mungkin bias yang terjadi pada saat pengumpulan dan analisis data.

Peneliti menggunakan triangulasi metode karena metode trianggulasi dilakukan dengan cara membandingkan informasi atau data dengan cara yang berdeda. Sebagaimana dikenal, dalam penelitian kualitatif peneliti menggunakan metode wawancara, obervasi, dan survei. Untuk 
memperoleh kebenaran informasi yang handal dan gambaran yang utuh mengenai informasi tertentu, peneliti bisa menggunakan metode wawancara bebas dan wawancara terstruktur. Atau, peneliti menggunakan wawancara dan obervasi atau pengamatan untuk mengecek kebenarannya. Selain itu, peneliti juga bisa menggunakan informan yang berbeda untuk mengecek kebenaran informasi tersebut. Menurut Patton (1987) dalam Bungin (2012) triangulasi sumber data yaitu:

1. Membandingkan data hasil pengamatan dengan hasil wawancara

2. Membandingkan apa yang dikatakan orang di depan umum dengan apa yang dikatakan secara pribadi

3. Membandingkan apa yang dikatakan orang-orang tentang situasi penelitian dengan apa yang dikatakan sepanjang waktu

4. Membandingkan keadaan dan prespektif seseorang dengan berbagai pendapat dan pandangan orang lain seperti rakyat biasa, orang berpendidikan menengah atau tinggi, orang berada dan orang pemerintahan

5. Membandingkan hasil wawancara dengan isi suatu dokumen yang berkaitan Selain menggunakan trigulasi, peneliti juga menggunakan data sekunder yang didapat secara tidak langsung. Peneliti mendapatkan data tersebut dari internet dan jurnal online.

\section{Product Placement}

Product/brand placement digunakan untuk meningkatkan pengetahuan akan merek (brand knowledge) diantara konsumen dalam setiap media beriklan yang digunakan (Panda, 2004). D'astous $\&$ Seguin mendefinisikan product placement dalam tiga jenis, yaitu:

\section{a. Implicit Product Placement}

Jenis ini disebut implisit karena merek, perusahaan atau produk ditampilkan dalam program/media tanpa ditekankan secara formal, dimana logo, nama merek/perusahaan muncul tanpa menampilkan/mendemonstrasikan product benefit (D'astous dan Seguin, dalam Panda, 2004).

b. Integrated Explicit Product placement

Jenis product placement ini berupaya mengintegrasikan secara eksplisit dimana merek atau nama perusahaan secara formal disebutkan dan memainkan peran aktif, serta atribut dan manfaat produk juga secara jelas ditampilkan (D'astous dan Seguin, di dalam Panda, 2004).

\section{c. Non-Integrated Explicit Product Placement} Jenis product placement ini menampilkan merek/perusahaan secara formal tapi tidak terintegrasi dalam isi program/media, umumnya ditampilkan di awal, di akhir atau dalam program title (D'astous dan Seguin, di dalam Panda, 2004). Russel (dalam Panda, 2004) membedakan product placement dalam tiga dimensi, yaitu visual, auditory \& plot connection. Dimensi visual terlihat pada munculnya merek/produk pada tampilan layar yang juga bisa disebut sebagai screen placement. Dimensi auditory adalah pada saat merek/produk disebutkan dalam dialog yang juga bisa disebut sebagai script placement. Dimensi plot connection sebagai dimensi ketiga digambarkan dengan seberapa merek/produk tersebut terintegrasi dalam cerita/story line.

2. Kelebihan dan Kekurangan Product Placement 
Pembahasan karakteristik brand/product placement dalam Fill (2006) terbagi atas dua bagian yaitu kelebihan (strengths) dan kekurangan (weakness) dari strategi ini.

a. Kelebihan Product/Brand Placement

Kelebihan dari product/brand placement adalah dengan menampilkan produk tersebut, bukan hanya memungkinkan untuk membangun awareness, kredibilitas bisa ditingkatkan secara signifikan serta dapat juga untuk memperkuat citra merek. Audience dalam hal ini didampingi untuk mengidentifikasi \& menghubungkan dirinya dengan lingkungan yang digambarkan atau dengan selebritis yang menggunakan produknya (Fill, 2006).

Kelebihannya yang lain (Rumambi, 2008) adalah dapat mengurangi biaya produksi, mencapai audience tertentu/captive audience, jangkauan yang lebih luas daripada periklanan tradisional, mendemonstrasikan kegunaan produk/merek dalam lingkup yang alami, menggambarkan setting yang lebih realistis serta menawarkan peluang beriklan bagi produk-produk yang dibatasi media iklannya seperti rokok \& alkohol.

b. Kekurangan Product Placement

Kekurangan product/brand placement Fill (2006) menyebutkan bahwa dengan menempatkan/melakukan placement di dalam film bukan berarti tidak ada resiko bahwa produk tersebut tidak akan terlihat (unnoticed), khususnya dalam kondisi ini apabila placement dilakukan pada adegan yang mengganggu/tidak menyenangkan (distracting). Selain itu yang juga berhubungan dengan kondisi ini, adalah tidak adanya kendali (lack of control) dari pengiklan atas kapan, dimana dan bagaimana produk tersebut akan ditampilkan. Saat produk itu muncul dan diperhatikan, sejumlah kecil/minoritas audience menyatakan bahwa bentuk komunikasi ini tidak etis (unethical), bahkan juga pernah disebut bahwa ini adalah bentuk subliminal advertising dimana bentuk ini disebut ilegal.

Absolute cost dari product placement dalam film bisa menjadi sangat tinggi apabila dihubungkan dengan low relative cost atau cost per contact. Hal lain juga menyebutkan bahwa kelemahan terkait dengan mediumnya adalah ketidakmampuan untuk menyediakan penjelasan, detil atau informasi penting (substantive information) tentang produk tersebut. Produk itu terlihat saat digunakan dan diharapkan dapat dihubungkan dengan kegiatan, individu atau obyek yang akan menyediakan source of pleasure, inspirasi atau aspirasi untuk individual viewer Fill (2006)..

\section{HASIL DAN PEMBAHASAN}

Semakin tinggi tingkat kesadaran akan suatu merek dalam benak konsumen, maka semakin besar kemungkinan merek tersebut dipertimbangkan dalam pembelian dan makin besar kesempatan merek tersebut untuk dipilih oleh konsumen.

Keuntungan dalam sebuah bisnis dapat dicapai apabila penjualan dalam suatu produk tinggi. Dalam halnya, perusahaan Le Minerale memikirkan strategi dalam upaya untuk mencapai tujuannya. Tujuan tersebut terwujud dengan adanya konsumen yang dimiliki oleh Le Minerale itu sendiri. Banyak dan loyalnya konsumen akan menentukan bahwa sebuah bisnis dapat berjalan lama atau tidak. Strategi yang dilakukan oleh Le 
Minerale adalah dengan melakukan product placement di beberapa social media dan program TV untuk meningkatkan strategi brand awareness mereka. Pemasaran yang digunakan oleh Le Minerale adalah untuk memperkenalkan merek maupun produknya kepada masyarakat. Adapun product placement yang dilakukan oleh Le minerale dalam meningkatkan brand awareness salah satunya yaitu:

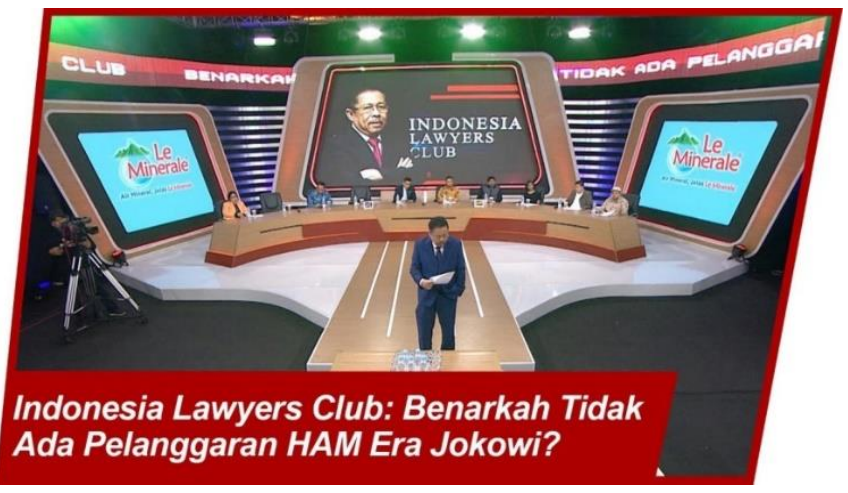

Gambar 4: ILC: Benarkah Tidak Ada Pelanggaran HAM Era Jokowi? (Sumber: YouTube Indonesia Lawyers Club)

Le Minerale sebelumnya sempat melakukan product placement pada acara televise Indonesia Lawyers Club dimana product terlihat pada layar belakang yang cukup bisa ternotice oleh penonton, dan juga beberapa produk yang diletakkan diatas meja. Acara Indonesia Lawyers Club sempat memiliki rating yang cukup tinggi dizamannya. Meski demikian, kini Teknologi telah merubah pola perilaku menonton TV saat ini, orang bisa mengakses berbagai program tayangan live TV dimanapun dan kapanpun melalui smartphone / gadget mereka masing-masing. Bahkan sekarang ini televise swasta telah memiliki akun resminya dimedia sosial seperti akun youtube, sehingga strategi product placement ini masih akan terus dapat memiliki pengaruhnya jika terdapat penonton yang menonton melalui social media seperti Youtube.

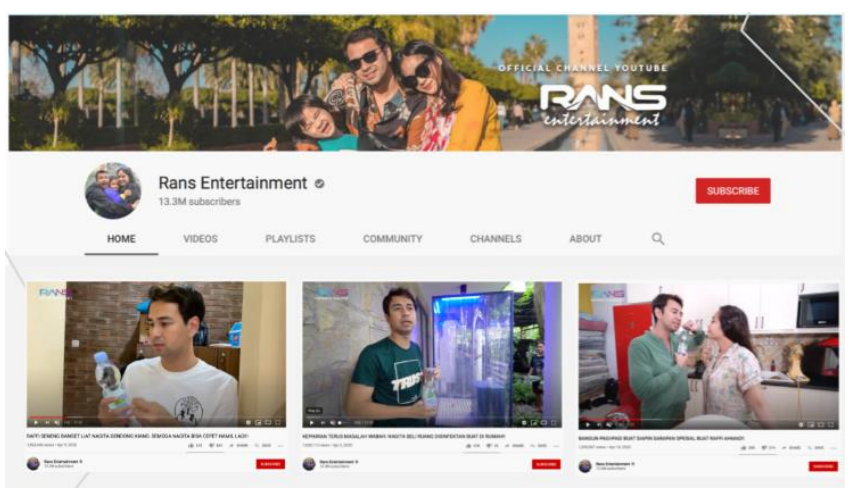

Gambar 5: YouTube Rans Entertainment (Sumber: YouTube Rans Entertainment) Terlihat product placement Le Minerale dipegang oleh Rafi Ahmad saat tayang di channel YouTube nya. Jenis product placement ini bernama Integrated Explicit Product placement, yaitu product placement yang berupaya untuk mengintegrasikan secara eksplisit dimana merek Le Minerale secara formal disebutkan dan memainkan peran aktif, produk dan manfaat produk juga secara jelas ditampilkan.

Dalam masa pandemic Covid-19 ini terlihat bahwa Raffi sedang mempromosikan ruang disinfektan yang dibelinya sekaligus memegang botol Le Minerale menjelaskan manfaat yang terkandung didalamnya. Pada video lainnya nagita menjelaskan bahwa kita sebagai masyarakat harus peduli dengan kesehatan dengan cara banyak minum air putih. Disini produk air mineral kemasan yag ditampilkan adalah Le Minerale.

Beberapa strategi ini menunjukan bahwa le minerale telah menjadi bagian dari kehidupan sehari-hari dan bagian dari pola hidup sehat dari pasangan Nagita Slavina dan Raffi Ahmad apalagi dimasa seperti sekarang ini dimana sedang pandemic Covid - 19. Strategi ini sangatlah 
menarik pasalnya product placement yang dilakukan le minerale tidak hanya satu video saja tapi pada beberapa video di channel Youtube Rans Entertainment yang kebanyakan video tersebut ditonton lebih dari 300.000 views. Hal ini tentu saja akan berpengaruh pada brand awareness dari product Le Minerale.

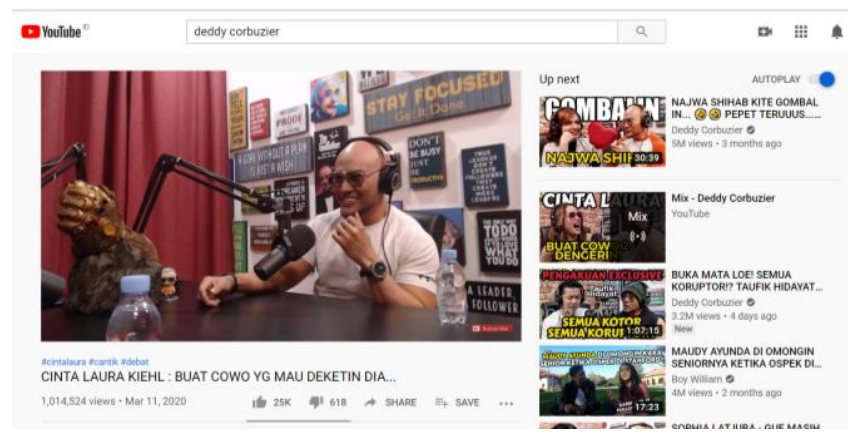

Gambar 6: Cinta Laura Kiehl: Buat Cowo Yg Mau Deketin Dia (Sumber: YouTube Deddy Corbuzier)

Le Minerale juga mencoba memanfaatkan akun youtube seorang Deddy corbuzier, diketahui bahwa video pada akun youtube ini lumayan sering mendapatkan voews yang banyak atau masuk kedalam trending. Adapun jenis product placement yang ada di channel YouTube Deddy Corbuzier ini disebut Implicit Product Placement karena produk yang ditampilkan dalam program acara YouTube ini tidak ditekankan secara formal, tanpa mendemonstrasikan product benefit. Sifat dari product placement ini pasif, sehingga nama merek, logo ataupun nama perusahaan muncul tanpa adanya penjelasan apapun mengenai manfaat atau kelebihan. Maka dari itu, agar promosi dalam product placement ini berjalan dengan efektif media yang digunakan dan target audience harus tepat. Contoh-contoh product placement bisa berupa masuk kedalam film, program-program televisi, video games, music, buku, sosial media seperti YouTube, Instagram, Facebook dan lain sebagainya.

Apabila dikaitkan dengan disepanjang masa pandemic Covid-19, tidak sedikit perusahaan yang bingung menyelamatkan cash flow di tengah kondisi yang tidak normal ini. Tapi saat inilah perusahaan ditantang untuk bertindak kreatif sekaligus produktif. Melihat permasalahan ini, cara Le Minerale untuk tetap bertindak kreatif adalah dengan memasang beberapa product placement untuk tetap selalu ada di benak konsumen dan meningkatkan brand awareness.

\section{SIMPULAN}

Hasil penelitian yang dilakukan membahas mengenai strategi peningkatan brand awareness melalui product placement menghasilkan kesimpulan bahwa keputusan masyarakat dalam memilih brand dikarenakan faktor brand awarenessnya, oleh karena itu Le Minerale berupaya memberikan pengaruh pada konsumennya melalui strategi iklan di beberapa media. Peneliltian mengenai product placement ini membahas untuk mengetahui strategi product placement yang digunakan Le Minerale agar menjadi top of mind. Dengan adanya pandemic Covid-19 ini, product placement yang digunakan oleh Le Minerale dapat meningkatkan brand awareness dimana orang banyak menghabiskan waktu dirumah dan lebih banyak menggunakan internet untuk menonton YouTube atau program televisi sehingga kedepannya cara yang dilakukan oleh Le Minerale dalam penempatan produknya dapat digunakan oleh brand lain untuk mempromosikan produk nya melalui social media atau media lainnya 


\section{DAFTAR PUSTAKA}

Aaker, David A. 2013. Manajemen Pemasaran Strategis. Jakarta: Salemba Empat

Annafik, A. F., dan M. Raharjo. 2012. Analisis Pengaruh Kualitas Produk, Harga dan Daya Tarik Iklan Terhadap Niat Beli Sepeda Motor Yamaha (Studi Kasus Pada Konsumen Yamaha SS Cabang Kudungmundu Semarang). Journal of Management, 1(2), hal.274-281.

Arif, A. (2020, April 27). Saat Wabah Covid-19, Social Media Marketing Jadi Pilihan Pemasaran Online. Retrieved from: https://www.ayosemarang.com/read/2020/04/27/5 6031/saat-wabah-covid-19-socialmediamarketing-jadi-pilihan-pemasaran-online

D’Astous. A, SeÂguin. Nathalie. (1998). “Consumer Reactions to Product placement Strategies in Television Sponsorship". European Journal of Marketing

Durianto, D., Sugiarto, and Budiman. 2004. Brand Ekuity Ten (Strategi Memimpin Pasar). Jakarta: PT Gramedia Pustaka Utama

Fill, C. (2006), Marketing CommunicationsEngagement, Strategies \& Practice (Fourth Edition).

Kotler, P., and K. L. Keller. 2012. Marketing Management, 13th Edition. New Jersey: Pearson Education, Inc

Kurniawan, F. (2019, 03 Juli). Konten Paling Populer di YouTube Indonesia: Vlog Keluarga. Retrieved From: https://tirto.id/konten-palingpopuler-di youtube-indonesia-vlog-keluargaedwU

Malik, M. E., M. Mudasar Ghafoor., and Hafiz Kashif Iqbal. 2013. Importance of Brand Awareness and Brand Loyalty in Assessing Purchase Intentions of Consumer. International Journal of Business and Social Science.

Nasrullah, R. (2017). Media Sosial: Perspektif Komunikasi, Budaya, dan Sosioteknologi. Bandung: Simbiosa Rekatama Media.

Panda, T.K. (2004). "Consumer Response to Brand Placements in Films Role of Brand Congruity and Modality of Presentation in Bringing Attitudinal Change Among Consumers with Special Reference to Brand Placements in Hindi Films". South Asian Journal of Management. Strategi Peningkatan Brand Awareness Yang Dilakukan Oleh Le Minerale Selama Masa Pandemi Covid-19
Retrieved

From: https://eprints.uny.ac.id/58054/1/IrfanaSurya

Dwiantana_13808141045.pdf

Riyanto, A. D. (2020, 17 August). Hootsite (We Are Social): Indonesian Digital Report 2020. Retrieved From: $\quad$ https://andi.link/hootsuite-we-are-socialindonesian-digital-report-2020/

Russell, Cristel A. (2002). Investigating the Effectiveness of Product placements in Television Shows: The Role of Modality and Plot Connection Congruence on Brand Memory and Attitude.

SocialBlade. (2020). Youtube user analytics. Retrieved from:

https://socialblade.com/youtube/channel/UCvA9_ f5Lwk poMynabtrZPg/monthly

Tasruddin, R. (2017). Trend Periklanan Di Media Sosial. Vol. 5 Retrieved from: http://journal.uinalauddin.ac.id/index.php/Kom odifikasi/article/download/ 504/4853

Wen, Ling-Yu Melody., and Shang-Hui Li. 2013. Consciousness, Ecological Affect, and Purchase Intention of Green Production. Journal of Organizational Innovation, 5(4), pp.124-137.

YouTube. (2019, 17 December). Cinta Laura Kiehl: Buat Cowo Yg Mau Deketin Dia. Retrieved From: https://youtu.be/spyPxcb8aIY

YouTube. (2019, 17 December). ILC: Benarkah Tidak Ada Pelanggaran HAM Era Jokowi?. Retrieved From: https://youtu.be/n-HD xEnzKU

YouTube. (2019, 17 December). YouTube Rans Entertainment. Retrieved From: https://www.youtube.com/channel/UCvA9_f5Lw k-poMynabtrZPg 